\title{
Effects of Aqueous and Ethanolic Extracts of Roasted and Ground Coffee Beans of Coffea canephora robusta on Glycemia and Release and Storage of Hepatic Glucose in Normoglycemic and Diabetic Rats
}

\author{
Aka F. B. Angelo ${ }^{1}$, Kablan A. L.Claude, ${ }^{2, *}$, Kati-Coulibaly Séraphin ${ }^{1}$ \\ ${ }^{1}$ Felix Houphouet Boigny University, Ivory Coast, Côte d'Ivoire \\ ${ }^{2}$ Peleforo Gon Coulibaly University of Korhogo, Ivory Coast, Côte d'Ivoire
}

Copyright $\bigcirc 2017$ by authors, all rights reserved. Authors agree that this article remains permanently open access under the terms of the Creative Commons Attribution License 4.0 International License

\begin{abstract}
The drink from the roasted and ground coffee beans of Coffea, which has been blamed, with alcohol, tobacco and drugs have been recognized for over a decade as a drink with positive effects on health. Among its benefits is an inverse association between low coffee consumption and high prevalence of type 2 diabetes. This study aims at evaluating the antidiabetic effects of an aqueous extract of roasted and ground beans of Coffea canephora robusta associated with a sulphonylurea (Glibenclamide) on glycaemia and on the release and storage of hepatic glucose among rats made diabetic by alloxan. Simultaneous oral administration of $20 \mathrm{mg} / \mathrm{kg}$ bw of aqueous extract of roasted and ground coffee beans of coffea canephora robusta +10 $\mathrm{mg} / \mathrm{kg}$ bw of glibenclamide after 28 days of treatment results in a highly significant decrease in blood glucose in diabetics rats, potentiating the effect of glibenclamide. Compared to aqueous and residual aqueous extracts, the ethanolic extract of roasted and ground beans of Coffea canephora robusta has a better inhibition of the release of hepatic glucose in the normoglycemic rats. After 90 days of treatment, the combination of coffee + glibenclamide favour more the storage of hepatic glucose compared with to diabetic rats treated only with glibenclamide. It appears that the aqueous extract of roasted and ground beans of Coffea canephora robusta would have antidiabetic properties and would act by supporting on the one hand the inhibition of the glycogenolysis and on the other hand the storage of hepatic glucose (glycogenogenesis). These results are quite in favour of the preventive effects from beverage resulting from roasted and ground Coffea in the appearance of type 2 diabetes.
\end{abstract}

Keywords Diabetes, Coffea canaphora robusta, Alloxane, Glycaemia, Glycogenogenesis, Glycogenogenesis

\section{Introduction}

The storage of carbohydrates and fatty acids form glycogen or triglycerides in peripheral tissues [1, 2]. This mechanism is under the control of insulin that regulates glycaemia level. However, a metabolic imbalance associated with a deficiency or lack of insulin secretion can occur and cause diabetes mellitus. Globally, there are 366 million people with diabetes with 3.2 million deaths a year [3]. A systematic meta-analysis of epidemiological studies between 1966 and 2009 on more than 457,000 subjects worldwide (in The Netherlands, the United States, Finland, Japan, Sweden, Singapore, Puerto Rico, United Kingdom) revealed a negative association between coffee consumption and the subsequent risk of developing type 2 diabetes [4]. In fact, there are no less than 73 species of Coffea but the only 2 actually exploited and sold in the world are Coffea arabica and Coffea canephora [5]. Compared to arabica, the robusta variety is cultivated in lowland and more humid conditions such as central and western Africa region, south-east Asia and some areas of Brazil [6]. The cherries of this coffee tree are round, small and thicker than those of arabicas [7]. The grains of this variety are sold cheaper on the market and often enter the composition of soluble coffees [8]. Robusta coffee accounts for just under $23.6 \%$ of world production [9]. The aim of this study is to evaluate the effects of an aqueous extract of roasted and ground beans of Coffea canephora robusta associated with a sulphonylurea (glibenclamide) on glycaemia and on the release and storage of hepatic glucose among rats diabetics.

\section{Materials and methods}

\subsection{Plant Material}

The plant material used is made up of roasted and ground 
beans of Coffea canephora robusta. These grains came from Côte d'Ivoire.

\subsection{Animal Material}

White rats Rattus norvegicus (Muridae) of Wistar parentage strain from the Pasteur Institute of Adiopodoumé (Abidjan, Cote d'Ivoire) weighing between 150 and $200 \mathrm{~g}$ are used for this study. These rats were reared in aerated metal cages metallic cage at $24 \pm 3^{\circ} \mathrm{C}$, with a 12-hour photoperiod and $50 \%$ hygrometry during 7 days were reared in aerated metal cages. They have ad libitum access to water and food.

\subsection{Preparation of Aqueous Extract of Roasted and Ground Beans of Coffea canaphora robusta}

The aqueous extract is obtained by infusion the roasted and ground beans of Coffea canephora robusta (Ccr). A filter coffee machine from Philips Daily collection in stainless steel timer isotherm HD7479 / 20 was used to prepare the coffee. The infusion was carried out with $30 \mathrm{~g}$ of roasted and ground Ccr grains in $175 \mathrm{ml}$ of distilled water. The filtrate obtained was evaporated in an oven at a temperature of $60^{\circ}$ C. The crystals obtained were pulverized. The collected fine powder was stored in refrigerated sterile glass jars in hermetically sealed glass. This technique made it possible to obtain $3 \mathrm{~g}$ of dry extract, corresponding to a yield of $10 \%$.

\subsubsection{Preparation of the Ethanolic Extract 70\% (EE) and Residual (ARE)}

The $70 \%$ and residual ethanolic extracts were obtained by dissolving $5 \mathrm{~g}$ of aqueous extract of roasted and ground coffee beans of Coffea canephora robusta in a mixer for 5 rotations of one minute in $100 \mathrm{ml}$ of an aqueous-alcoholic solution ( $70 \%$ methanol) [10]. The collected homogenate was introduced into a separating funnel, which separates it into two phases, a hydroalcoholic phase and the residue. These two phases were then dried in an oven at $50^{\circ} \mathrm{C}$. This technique made it possible to obtain $3.655 \mathrm{~g}$ of ethanolic extract and $1.045 \mathrm{~g}$ of aqueous residual extract, corresponding respectively to a yield of $73.3 \%$ and $20.9 \%$.

\subsection{Preparing the Mac Ewen Solution}

One litre of Mac Ewen's solution was made up of $130 \mathrm{mM}$ $\mathrm{NaCl} ; 5.63 \mathrm{mM} \mathrm{KCl} ; 12.16 \mathrm{mM} \mathrm{CaCl} 2 ; 0.91 \mathrm{mM} \mathrm{H} 2 \mathrm{PO} 4 \mathrm{Na}$; $11.90 \mathrm{mM} \mathrm{HCO} 3 \mathrm{Na}$ and $0.25 \mathrm{mM} \mathrm{MgCl} 2.2 \mathrm{~g}$ of glucose were added to this physiological solution before the experiments. The Mac Ewen glucose was used for the study of the release of glucose from the isolated liver of rats.

\subsection{Chemical and Pharmaceutical Products}

Alloxan (Alfa Aesar, Germany) is a diabetogen which is administered intraperitoneally and destroys $\beta$ cells in the islets of langerhans and induces experimental diabetes. Glibenclamide (Sanofi aventis, France) is an antidiabetic substance (sulphonylurea) which stimulates the secretion of insulin by the pancreas.

\subsection{Measurement of Glucose Released from the Liver of Normoglycemic Rats}

\subsubsection{Principle}

In the presence of glucose oxidase (GOD), glucose is oxidized into gluconic acid. The released hydrogen peroxide during the reaction reacts under the action of peroxidase (POD) with phenol and amino-4-phenazole to form a pink complex. The intensity of the coloration is proportional to the concentration of glucose in the sample.

\subsubsection{Experimental Protocol}

This study was carried out on 30 normoglycemic Wistar rats with a body weight (b.w) of between 150 and 200 g. These animals were shared into 5 groups. The animals in batch 1 (control) were gavaged with distilled water for 28 days (duration of the experiment). Those of batchs 2, 3 and 4 were treated with the aqueous extract (AE), the aqueous residual extract (ARE) and the ethanolic extract (EE) of roasted and ground coffee beans of Coffea canephora robusta (Ccr) respectively of $20 \mathrm{mg} / \mathrm{kg}$ PC, $5 \mathrm{mg} / \mathrm{kg}$ b.w and $100 \mathrm{mg} / \mathrm{kg}$ b.w [11]. The rats of batch 5 were treated with a dose of $10 \mathrm{mg} / \mathrm{kg}$ b.w of glibenclamide. After 28 days of treatment, the animals were sacrificed and a liver fragment weighing $2 \mathrm{~g}$ was taken from each of the rats of each batch. The liver fragments collected in batches 1, 2, 3, 4 and 5 were immersed in S1, S2, S3, S4 and S5 solutions containing $4 \mathrm{ml}$ of glucosed Mac-Ewen respectively and incubated at $37^{\circ} \mathrm{C}$ for 60 minutes. The supernatant of each solution was taken away to close the amount of glucose in the presence of the GOD-POD (reagent) glucose. This assay was carried out using a spectrophotometer (Biolabo, France), at $500 \mathrm{~nm}$, at times $0 \mathrm{~min}$ (before the solutions were put into solution), then $10 \mathrm{~min}, 20 \mathrm{~min}, 30 \mathrm{~min}, 40 \mathrm{~min}, 50 \mathrm{Min}$ and $60 \mathrm{~min}$ after immersion of organs in the Mac Ewen glucose solution.

\subsection{Study of the Effects of the Simultaneous Intake of the Aqueous Extract of Roasted and Ground Beans of Coffea canephora robusta $(\mathrm{Ccr})$ and Glibenclamide on the Glycemia of Diabetic rats}

\subsubsection{Glycaemia Measurement}

Blood glucose of diabetics rats was measured by using an Accu-Chek Active glucometer and test strips (Roche diagnosis, Germany). In this study, the rats were fasted for 12 hours before the experiments. The substances to be tested were administered orally.

\subsubsection{Experimental protocol}

This study was carried out on $30 \mathrm{Wistar}$ rats distributed in 5 batchs. Their weight varies between 150 and $200 \mathrm{~g}$. batch 1 , normoglycemic control, received distilled water. Lot 2 constitutes the diabetic control (DC) similarly received 
distilled water. Diabetics rats of batches 3,4 and 5 were treated with $20 \mathrm{mg} / \mathrm{kg}$ b.w of aqueous extract of roasted and ground beans of Coffea canephora robusta (DTC20), simultaneously $20 \mathrm{mg} / \mathrm{kg}$ b.w of aqueous grain extract roasted and ground coffee of Coffea canephora robusta +10 $\mathrm{mg} / \mathrm{kg}$ of glibenclamide b.w (DTC $20+\mathrm{G}$ ) and glibenclamide at $10 \mathrm{mg} / \mathrm{kg}$ b.w (DG). The experiment lasts 28 days and blood glucose was measured at time D0 (before the start of gavage), then on the 7th, 14th and 28th day after the gavage.

\subsection{Measurement of Glucose Stored in the Liver of Diabetic Rats}

\subsubsection{Principle}

The dosage of glucose stored by the liver is done in the presence of the GOD-POD glucose reagent.

\subsubsection{Experimental Protocol}

This study was carried out on 30 Wistar rats distributed in 5 batches. Their weight varies between 150 and $200 \mathrm{~g}$. Batch 1 , normoglycemic control, received distilled water. Batch 2 constitutes the diabetic control also received distilled water. Diabetics rats batches 3, 4 and 5 were treatedwith $20 \mathrm{mg} / \mathrm{kg}$ b.w of aqueous extract of roasted and ground beans of Coffea canephora robusta (batch 3), $10 \mathrm{mg} / \mathrm{kg}$ b.w of glibenclamide (batch 4) and simultaneously $20 \mathrm{mg} / \mathrm{kg}$ b.w of aqueous extract of roasted and ground coffee beans of Coffea canephora robusta $+10 \mathrm{mg} / \mathrm{kg}$ of glibenclamide b.w (batch 5). After 90 days of treatment, the animals were sacrificed and a lobe weighing $5 \mathrm{~g}$ of liver was taken from each of the rats of each batch, cut into small pieces and then ground in 30 $\mathrm{ml}$ of $4 \%$ trichloroacetic acid. The ground product obtained was placed in a test tube and centrifuged at $4500 \mathrm{rpm}$ during $10 \mathrm{~min}$, then the supernatant was recovered. $95 \%$ ethanol was then added to the supernatant (ethanol / supernatant, $2 \mathrm{v}$ $/ \mathrm{v})$, the mixture was stirred and heated in a slow-boiling water bath to boiling point. The glycogen precipitates and the suspension obtained was cooled and centrifuged at $4500 \mathrm{rpm}$ for $10 \mathrm{~min}$. To the pellet (precipitated glycogen) were added 2 $\mathrm{ml}$ of $2.5 \mathrm{~N}$ sulfuric acid (H2SO4) and the tube was heated for 30 minutes. This step allows the hydrolysis of glycogen to glucose. After the hydrolysis, the tube was cooled and 1 drop of dinitrophenolphthalein was added, followed by $2.5 \mathrm{~N}$ sodium hydroxide until a red-pink turning coloration. This step made it possible to neutralize the acidity of the hydrolyzate. For each sample, the glucose thus formed was assayed by the Beer colorimetric method [12] in the presence of the GOD-POD reagent [13]. The glucose formed was dosed using a spectrophotometer (Biolabo, France), at 500 $\mathrm{nm}$.

\subsection{Methods of Statistical Analysis and Treatment of Results}

Data analysis and graph plotting were performed using Graph Pad Prism 5 software (San Diego CA, USA). The results are given as a mean followed by the standard error on the mean $(\mathrm{M} \pm \mathrm{ESM})$. The difference between two values was determinated by the Student-Newman-Keuls test and was considered slightly significant for $(\mathrm{p}<0.05)$; Significant for $(p<0.01)$ and highly significant for $(p<0.001)$.

\section{Results}

The glucose concentration of each of the glucosed Mac Ewen solutions before the experiment was $2 \pm 0.01 \mathrm{~g} / \mathrm{L}$. The glucose concentration of the control solution (S1) containing the liver of the control rats given distilled water increased from $2 \pm 0.01 \mathrm{~g} / \mathrm{L}$ at the start of the experiment to $2.45 \pm 0.02$ $\mathrm{g} / \mathrm{L}$ at the end of the experiment; that is to say $22.5 \%$ increase in the glucose level. The glucose concentrations of the S2, S3 and S4 solutions which received the liver from the aqueous extract (TAE) rats, the aqueous residual extract (TARE) and the ethanol extract (TEE) at the respective doses of $20 \mathrm{mg} / \mathrm{kg}$ b.w, $5 \mathrm{mg} / \mathrm{kg}$ b.w and $100 \mathrm{mg} / \mathrm{kg} \mathrm{b.w}$, were $2.43 \pm 0.02 \mathrm{~g} / \mathrm{L}$; $2.40 \pm 0.03 \mathrm{~g} / \mathrm{L}$ and $2.27 \pm 0.02 \mathrm{~g} / \mathrm{L}$ respectively at the end of the experiment. In these solutions, the glucose level therefore increases by $21.5 \%$ (S2), $20 \%$ (S3) and $13.5 \%$ (S4) compared with the initial concentration of glucose. In the S5 solution containing the liver of glibenclamide $(\mathrm{G})$ treated rats at $10 \mathrm{mg} / \mathrm{kg}$ b.w, the glucose concentration at the end of the experiment was $2.24 \pm 0.03 \mathrm{~g} / \mathrm{L}$; or $12 \%$ increase over the initial glucose concentration. The evolution of the hepatic glucose level in the $\mathrm{S} 2$ solution is substantially equal to that of the glucose level in the S1 solution. However, compared to the glucose level of the $\mathrm{S} 1$ control solution, the glucose concentrations of the S3, S4, S5 solutions decreased slightly $(\mathrm{P}<0.05)$. Indeed, at the end of the experiment, the glucose level is reduced by $2.04 \%$ (S3); $7.34 \%$ (S4) and $8.57 \%$ (S5), compared to the control solution S1.

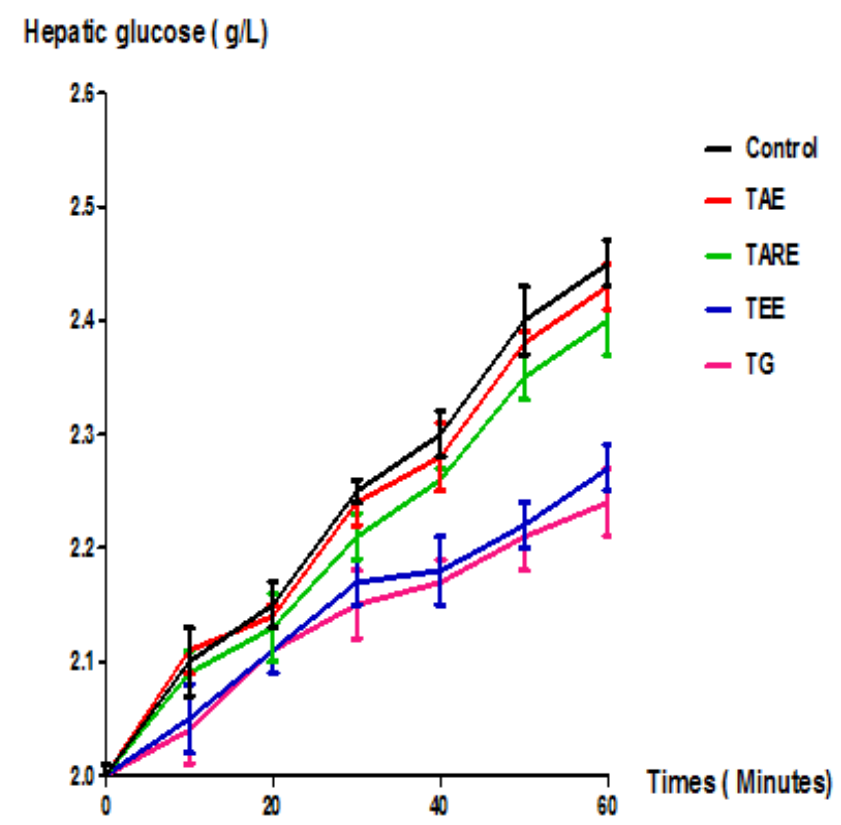

Figure 1. Dose-response effects of aqueous extract (AE), aqueous residual extract (ARE) and ethanolic extract (EE) of roasted and ground beans of Coffea canaphora robusta and glibenclamide $(\mathrm{G})$ on the release of hepatic glucose from normoglycemic rats 


\subsection{Effects of the Simultaneous Intake of the Aqueous Extract of Roasted and Ground Beans of Coffea canaphora robusta and Glibenclamide on the Glycemia of Diabetic Rats}

The blood glucose levels of the different batches of diabetic rats average $2.67 \pm 0.25 \mathrm{~g} / \mathrm{L}$, corresponding to an increase of $203.40 \%$ compared to normoglycemic rats $(0.88$ $\pm 0.03 \mathrm{~g} / \mathrm{L})$ ).

At day 14 , in diabetic rats treated with glibenclamide (DTG) and simultaneously with $20 \mathrm{mg} / \mathrm{kg}$ b.w of aqueous extract of roasted and ground coffee beans of Coffea canephora robusta $+10 \mathrm{mg} / \mathrm{kg}$ PC of glibenclamide $($ DTC $20+G)$, we observed a highly significant decrease in blood glucose $(p<0.001)$ of $47.37 \%$ and $51.13 \%$, respectively, compared to untreated control diabetic rats (DC). Otherwise, on the one hand we observed a non-significant decrease $(\mathrm{p}>0,05)$ in the glycemia of the rats treated only with the coffee beverage at a dose of $20 \mathrm{mg} / \mathrm{kg}$ bw (DTC20) of the order of 4, 13\% compared to untreated control diabetic rats, and a slight significant variation in blood glucose ( $p>0.05$ ) between the 2 batches of diabetic rats treated with DTG and DTC20+G.

At day 28, in diabetic rats treated with DTG and DTC20+G, blood glucose reduction was still highly significant $(\mathrm{p}<0.001)$ with 56.77 and 62.41 percent, respectively, compared to untreated control diabetic rats. In contrast to the 14th day, we observed a slight decrease $(p<0.05)$ in blood glucose levels in rats (DTC20) treated only with the coffee drink at a dose of $20 \mathrm{mg} / \mathrm{kg}$ bw (6.01\%) compared to untreated control diabetic rats and a significant decrease $(p<0.01)$ in the glycemia of diabetic rats treated with DTP20+G compared to DTG treated rats.

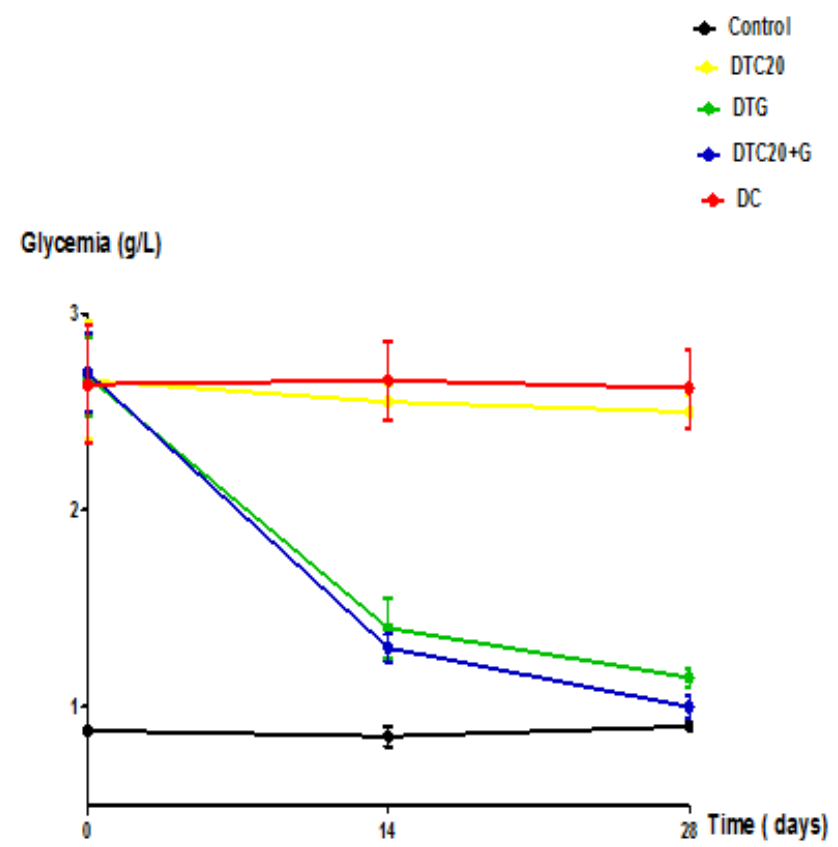

Figure 2. Effects of aqueous extract of roasted and ground beans of Coffea canephora robusta (Ccr),glibenclamide (G) and their simultaneous glucose in diabetic rats

\subsection{Effects of the Simultaneous Intake of Aqueous Extract of Roasted and Ground Beans of Coffea canephora robusta (Ccr) and Glibenclamide on Hepatic Glucose Stored in the Liver of Diabetic Rats}

At the end of the 90-day experiment, in normal control rats (untreated normoglycemic control rats) the stored hepatic glucose level was $0.57 \pm 0.06 \mathrm{~g} / \mathrm{L}$. That is to say, among the diabetic control rats (DC), the stored hepatic glucose level was $0.28 \pm 0.04 \mathrm{~g} / \mathrm{L}$; or a decrease in the stored hepatic glucose level of $50.87 \%(p<0.001)$ compared to normal control rats. When diabetic animals are treated with aqueous extract of roasted and ground coffee beans at a dose of $20 \mathrm{mg} / \mathrm{kg}$ bw (DTC20) or glibenclamide at a dose of $10 \mathrm{mg} / \mathrm{kg}$ bw (DTG) aqueous extract of roasted and ground coffee beans at a dose of 20 $\mathrm{mg} / \mathrm{kg}$ bw $+10 \mathrm{mg} / \mathrm{kg}$ bw glibenclamide (DTC20+G), the stored hepatic glucose levels measured are respectively $0.35 \pm 0.06 \mathrm{~g} / \mathrm{L} ; 0.49 \pm 0.05 \mathrm{~g} / \mathrm{L}$ and $0.55 \pm$ $0.04 \mathrm{~g} / \mathrm{L}$ are respectively increases in stored hepatic glucose levels of $25 \% \quad(p<0.05), 75 \%$ and $96.43 \%$ $(p<0.001)$ compared to untreated diabetic rats. Compared to healthy control rats, when diabetic rats were treated with glibenclamide at $10 \mathrm{mg} / \mathrm{kg}$ bw or simultaneously with aqueous extract of roasted and ground coffee beans at a dose of $20 \mathrm{mg} / \mathrm{kg} \mathrm{bw}+10 \mathrm{mg} / \mathrm{Kg}$ bw glibenclamide, measured hepatic glucose slight levels decreased significantly $(\mathrm{p}<0.05)$ or remained substantially identical $(p>0.05)$. Therefore, compared to the diabetic rats treated simultaneously with the aqueous extract of roasted and ground coffee beans at a dose of $20 \mathrm{mg} / \mathrm{kg}$ bw +10 $\mathrm{mg} / \mathrm{kg}$ bw glibenclamide, measured hepatic glucose slight levels decreased significantly $(\mathrm{p}<0.05)$ compared to rats treated only with glibenclamide at a dose of $10 \mathrm{mg} / \mathrm{kg}$ bw.

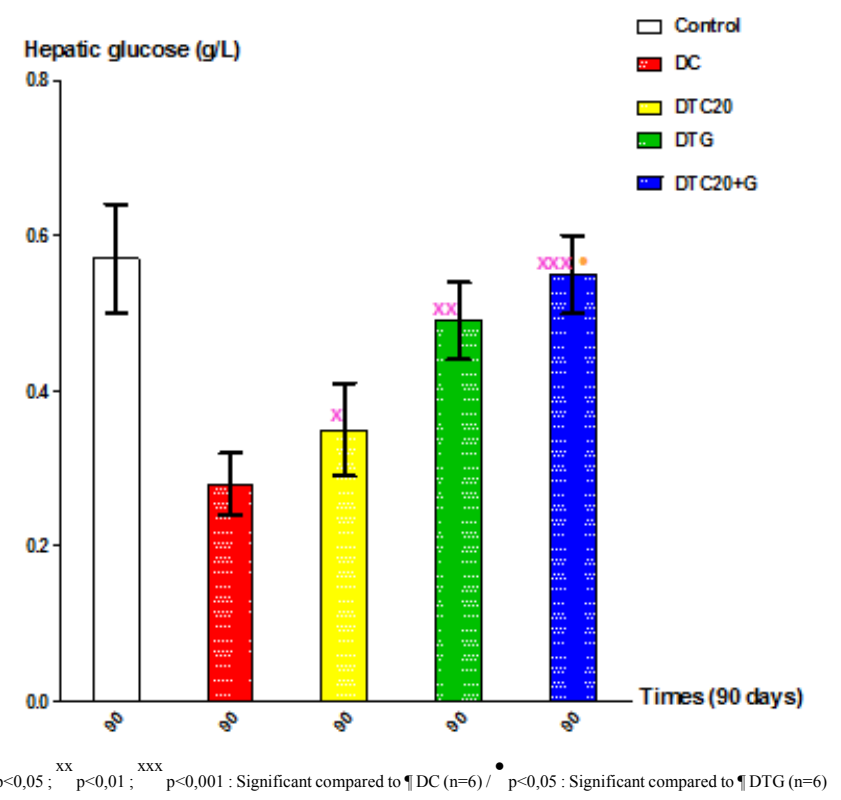

Figure 3. Effects of the aqueous extract of roasted and ground beans of Coffea canephora robusta (Ccr), glibenclamide (G) and their simultaneous administration on the storage of hepatic glucose from rats 


\section{Discussion}

The glucose released by the liver from normoglycemic control rats and normoglycemic rats treated with the various extracts of roasted and ground beans of Coffea canephora robusta or with glibenclamide increases progressively according to the time. It should therefore be concluded that the liver releases glucose. This result is similar to that of Claude Bernard, who, in 1853, showed that under physiological conditions the liver releases glucose to meet the physiological needs of the organism [14]. The production of hepatic glucose and its release into the bloodstream would be due to the hydrolysis of glycogen to glucose by the enzyme glycogen phosphorylase [15]. Compared to control normoglycemic rats, the treatment of normoglycemic rats with aqueous extract (AE), aqueous residual extract (ARE) and ethanolic extract (EE) of roasted and ground coffee beans of Coffea canephora robusta at the respective doses of $20 \mathrm{mg} / \mathrm{kg} \mathrm{bw}, 5 \mathrm{mg} / \mathrm{kg}$ bw and $100 \mathrm{mg} / \mathrm{kg}$ bw leads to a decrease in the glucose released by the liver. The glucose release from the liver of rats treated with ethanolic extract (EE) at $100 \mathrm{mg} / \mathrm{kg}$ bw was substantially identical to that of rats treated with glibenclamide at a dose of $10 \mathrm{mg} / \mathrm{kg} \mathrm{bw}$. This highly significant reduction in hepatic glucose release with ethanol extract (TEE) could be explained by the much larger presence of phenolic compounds such as chlorogenic acid in the extract. Indeed, chlorogenic acid would inhibit the glucose-6-phosphatase enzyme at the hepatic level, which results in a decrease in intestinal absorption of glucose [18]. Recently, it has been reported that chlorogenic acid also activates adenosine monophosphate-activated protein kinase, a sensor and regular of cellular energy balance, leading to beneficial metabolic effects, such as suppression of hepatic glucose production and fatty acid synthesis [19]. The injection of alloxan monohydrate into rats results in an increase in blood glucose from $0.88 \pm 0.03 \mathrm{~g} / \mathrm{L}$ to $2.67 \pm 0.25$ $\mathrm{g} / \mathrm{L}$ and is maintained, reflecting the installation of diabetes experimental after necrosis of the pancreatic $\beta$ cells. This hyperglycemia persists during the 28 days of experiment in untreated diabetic rats. When diabetic rats are treated with glibenclamide at a dose of $10 \mathrm{mg} / \mathrm{kg}$ bw or simultaneously 20 $\mathrm{mg} / \mathrm{kg}$ bw aqueous extract of roasted and ground beans of Coffea canephora robusta $+10 \mathrm{mg} / \mathrm{kg}$ bw of glibenclamide, hyperglycemia decreases significantly and blood sugar levels tend to return to normal. Chu et al. have demonstrated that, thanks to coffee, adipocytes absorb plasma glucose more rapidly, which would have a positive hypoglycaemic effect [20]. The same effect was observed by Mai Abd Al [21] who associated glimepiride + Trigonella foenum graceum (fenugreek) and glimepiride + coffee drink in the treatment of diabetic rats. Similarly, daily intake of $1 \mathrm{~g}$ of hydroalcoholic extract of seeds of the same plant (fenugreek) in combination with glibenclamide also improved glycemic control and decreased insulin resistance among 25 patients with diabetes mellitus Type II newly diagnosed [22]. Some studies on other plants associated with glibenclamide in the treatment of experimental diabetes induced in animals have demonstrated a reduction in hyperglycemia such as the association of aqueous extract of roasted and ground beans Coffea canephora robusta + glibenclamide in this study.

Considering Coffea, Campus-Florian Julio et al. [27] obtained a significant decrease in hyperglycaemia up to normal glycemic levels by treating diabetic rats only with the aqueous extract of Coffea arabica green beans at 63 and 93 $\mathrm{mg} / \mathrm{kg}$ bw. Shradha Bisht et al. [28] observed the same effects of decreased hyperglycaemia in rats rendered diabetic by streptozotocin and treated with an ethanol extract of Coffea arabica grains. We can deduce from our study that the aqueous extract of the roasted and ground beans of Coffea canephora robusta, like glibenclamide, possesses antidiabetic properties. Indeed, glibenclamide, administered on an empty stomach, stimulates insulin secretion, decreases glucagon secretion, inhibits hepatic release of glucose and potentiates the effects of insulin on the liver [29]. In rats rendered diabetic by alloxan monohydrate, the stored hepatic glucose level was reduced by $50.87 \%$ compared to non-diabetic control rats. The decrease in hepatic glucose storage observed in diabetic rats is explained by an alteration of insulin secretion after administration of the alloxan monohydrate. Indeed, Elsner et al. [30] and Shetti et al. [31] showed that alloxan alters the secretion of insulin, resulting in inhibition of glucokinase activity. When diabetic rats are treated simultaneously with $20 \mathrm{mg} / \mathrm{kg}$ bw of aqueous extract of roasted and ground coffee beans of Coffea canephora robusta $+10 \mathrm{mg} / \mathrm{kg}$ bw of glibenclamide after 90 days the stored hepatic glucose increases significantly and becomes substantially identical to that of the normal control rats. These results show that the aqueous extract of the roasted and ground beans of Coffea canephora robusta potentiates the action of the sulphonylurea hypoglycemic (glibenclamide) favoring more the storage of the glucose in the liver compared to the rats treated only with glibenclamide at the dose of $10 \mathrm{mg} / \mathrm{kg}$ bw. It may therefore be suggested that, like glibenclamide, the mechanism of action of the aqueous extract of roasted and ground beans of Coffea canaphora robusta depends on its direct action on Glut2 receptors (glucose transporter in the cell) or stimulation of residual $\beta$ cells of the pancreas to allow the storage of glucose.

\section{Conclusions}

The regulation of blood glucose involves the hormonal system as well as several organs (pancreas, liver, kidney). This regulation is part of the processes of maintaining homeostasis within the organism. The ethanolic extract of roasted and ground beans of Coffea canaphora robusta inhibits the release of hepatic glucose (glycogenolysis) in normoglycemic rats. Similarly, the aqueous extract of roasted and ground beans of Coffea canaphora robusta reduces hyperglycaemia in diabetic rats. However, this same aqueous extract potentiates the action of glibenclamide by 
further promoting the storage of glucose in the liver (glycogenogenesis) in alloxanic diabetic rats. These results are in favor of the preventive effect of the beverage from the roasted and ground Coffea (coffee) beans on the occurrence of type 2 diabetes.

\section{Acknowledgements}

We thank Kablan Landry and KATI-COULIBALY Séraphin for their valuable assistance with consultation, data collection, and administrative assistance. The authors' responsibilities were as follows - Landry: designed the research (project conception, development of the overall research plan, and study oversight) and had primary responsibility for the final content; Séraphin: analyzed the data; Landry: designed the research and performed the statistical analysis; Landry and Séraphin: wrote the paper; and all authors: read and approved the final manuscript. None of the authors reported a conflict of interest related to the study.

\section{REFERENCES}

[1] Claude B., 1853. Recherche sur une nouvelle fonction du foie, considéré comme organe producteur de matière sucrée chez l'homme et les animaux. Thèse de doctorat de Zoologie de la Faculté des Sciences de Paris (France), 99 p.

[2] Moussard C., 2006. Biochimie structurale et métabolique, De Boeck, $187 \mathrm{p}$.

[3] Whiting D. R., Guariguata L., Weil C. S. J., 2011. IDF Diabetes Atlas Global estimates of the prevalence of diabetes for 2011 and 2030. Diabetes Research and Clinical Practice, 94: $311-321$

[4] Huxley R et al. Coffee, Decaffeinated Coffee, and Tea Consumption in Relation to Incident Type 2 Diabetes Mellitus. Arch Intern Med 2009; 169: 2053-63.

[5] Campa C., Doulbeau S., et al ; 2005. Diversity in bean caffeine content among wild Coffea species: Evidence of a discontinuous distribution. Food Chemistry. 91, pp 633-637.

[6] http://www.ico.org/prices/m1.htm I.C.O, 2011.

[7] LambardCh.«Lecafédelaterreàlatasse».CentredeCaféologie.B ordeaux(France),2003.

[8] FAO. (Food and Agriculture Organization) Manual on the application of the HACCP system in mycotoxin prevention and control. Food and Nutrition, 2001; 73. ISSN 0254-4725.

[9] Costro L, Mourad AL, Oliveira PAPLV, Braddini JPOA, Kletecke RM. Environmental profile of Brazilian green coffee. International Journal J.L.C.A, 2006; 11: 16-21.

[10] G. N. Zirihi, A. M. Kra et F. Guédé-Guina,. Évaluation de lactivité antifongique de Microglossa pyrifolia (LAMARCK) O. KUNZE (ASTERACEAE) $<<$ PYMI $>>$ sur la croissance in vitro de Candida albicans". Revue de Med. et Pharm. Afr., 2003; 17: 11-18.
[11] AKA Francis B.A., Amonkan K.A., et al ; 2017. Hypoglycemiant and anti-hyperglycemiant effects of the aqueous extract of roasted and ground coffee beans of coffea canephora robusta in the wistar rat. European journal of pharmaceutical and medical research. ejpmr, 2017,4(05), 181-189.

[12] Beer A., 1852. Bestimmung der Absorption desrothen Licht in farbigen Flüssigkeiten. Annal en der Physik und Chemie, 86: 78-88.

[13] Trinder P., 1969. Determination of glucose in blood using glucose oxidase with an alternative oxygen acceptor. Ann Clin Biochem, 6:24-27.

[14] ClaudeB., 1853. Recherche sur une nouvelle fonction du foie, considéré comme organe producteur de matière sucrée chez l'homme et les animaux. Thèse de doctoratde Zoologie de la Faculté des Sciences de Paris (France), 99 p.

[15] Madsen N.B., 1991. Glycogen phosphorylase and glycogen synthetase; in kuby. A study of nzymes, 2:139-158.

[16] Van Dam RM, Feskens EJ. The Lancet. 2002. Op.cit.

[17] Ong KW, Hsu A, Tan BK, 2013. Anti-diabetic and anti-lipidemic effects of chlorogenic acid are medialeted by ampk activation. Biochem Pharmacol 85: 1341-1351.

[18] CHU Y.-F., CHEN Y., BLACK R. M. et al. "Type 2 diabetes-related bioactivities of coffee: Assessment of antioxidant activity, NF- $\mathrm{BB}$ inhibition, and stimulation of glucose uptake». Food Chemistry [En ligne]. février 2011.Vol.124, n³, p.9146-920.

[19] Mai Abd Al-Khalik Gharib., 2016. Glycemic reaction of glimepiride combined with popular Egyptian antidiabetic drinks of fenugreek and coffee in diabetic rats. Pakistan Journal of Nutrition 15 (2): 194-202.

[20] A. Gupta, R. Gupta, and B. Lal, "Effect of Trigonella foenum-graecum (Fenugreek) seeds on glycaemic control and Insulin resistance in type 2 Diabetes Mellitus : a double blind placebo controlled study," Journal of Association of Physicians of India, vol. 49, pp. 1057-1061, 2001

[21] JulioCampos-Florián, JessicaBardales-Valdivia., etal; 2013. Anti-diabetic effect of Coffea arabica, in alloxan induced diabeticrats. Emir.J.FoodAgric.2013.25(10):772-777.

[22] Shradha Bisht, S.S. Sisodia. 2011. Protective Role of Coffee Beans in Diabetes Mellitus Model of Rats. Journal of Pharmacy Research 2011, 4(10), 3717-3720.

[23] Jackson J. E. et Bressler R., 1981. Clinical pharmacology of sulphonylurea hypoglycemic agents. Part I. DRUG; 212:211-245.

[24] Elsner M., Tiedge M., Guldbakke B., Munday R., Lenzen S., 2002. Importance of the GLUT2 glucose transporter for pancreatic beta cell toxicity of alloxane. Diabetologia, 45:1542-1549.

[25] ShettiA. A., Sanakal R. D., KaliwalB. B., 2012. Antidiabetic effect of ethanolic leaf extract of Phyllantus amarus in alloxan induced diabetic mice. [34] A. Trejo-González, G. Gabriel-Ortiz, A. M. Puebla-Pérez et al., "A purified extract from prickly pear cactus (Opuntia fuliginosa) controls experimentally induced diabetes in rats," Journal of Ethnopharmacology, vol. 55, no. 1, pp. 27-33, 1996. 